\title{
Laboratory Diagnosis of Tuberculosis in Primary Care
}

David Brett-Major

University of Nebraska Medical Center, david.brettmajor@unmc.edu

Thomas E. Walsh

National Naval Medical Center

Tell us how you used this information in this short survey.

Follow this and additional works at: https://digitalcommons.unmc.edu/coph_epidem_articles

Part of the Epidemiology Commons

\section{Recommended Citation}

Brett-Major, David and Walsh, Thomas E., "Laboratory Diagnosis of Tuberculosis in Primary Care" (2006). Journal Articles: Epidemiology. 17.

https://digitalcommons.unmc.edu/coph_epidem_articles/17

This Article is brought to you for free and open access by the Epidemiology at DigitalCommons@UNMC. It has been accepted for inclusion in Journal Articles: Epidemiology by an authorized administrator of DigitalCommons@UNMC.For more information, please contact digitalcommons@unmc.edu. 


\title{
Laboratory Diagnosis of Tuberculosis in Primary Care
}

\author{
David M. Brett-Major, MD, and \\ Thomas E. Walsh, MD, FCCP
}

\section{Introduction}

This component of the series on tuberculosis in primary care will focus on laboratory diagnosis. Despite the advances in diagnosis described here, up to $20 \%$ of U.S. tuberculosis cases are clinically diagnosed. ${ }^{1}$ Recommendations for the core laboratory features of a tuberculosis control program include $^{2}$ the following:

Rapid microscopic evaluation for acid-fast bacilli;

Nucleic acid amplification assay (NAA/polymerase chain reaction (PCR)) of collected sample;

Culture, with detection and subsequent identification of samples within 3 weeks (which presupposes use of automated broth culture methods); and,

Drug susceptibility testing for both first- and second-line drugs (usually performed at the state lab or national referral center level).

The evidence on laboratory diagnosis of tuberculosis allows a systematic approach to testing in a given patient (Fig 1). Details regarding specimen collection and handling for various anatomic sites are published. ${ }^{3,4}$ Note that while some settings enjoy a high diagnostic yield by laboratory methods, no modality is sufficient in isolation. Smear and culture-negative tuberculosis is a common phenomenon. ${ }^{5} \mathrm{CDC}$ surveillance data from 2004 reveals $42 \%$ smear-negative and 17\% culturenegative rates for pulmonary tuberculosis. ${ }^{1}$ Smear-negative index cases contribute to as much as $17 \%$ of newly transmitted cases. ${ }^{6}$

\section{Bacteriology and Microscopy}

Tuberculosis is caused by a bacillus of the Mycobacterium tuberculosis complex. The most common of the group, $M$. tuberculosis, is a respiratory pathogen communicable between infected humans. While different au-

Dis Mon 2006;52:450-458

$0011-5029 / 2006 \$ 32.00+0$

doi:10.1016/j.disamonth.2006.09.011 


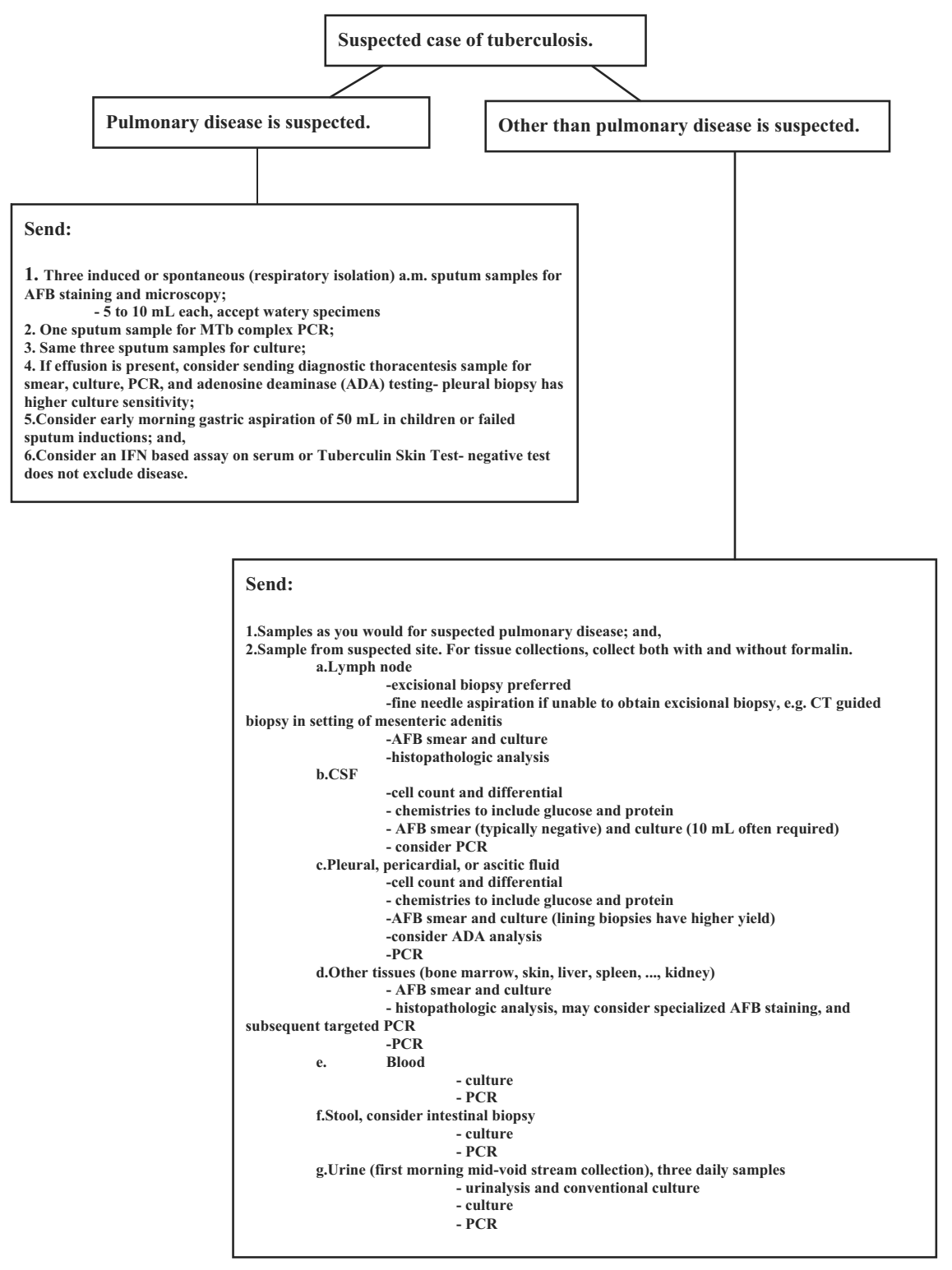

FIG 1. Clinical algorithm for the laboratory diagnosis of tuberculosis.

thors cite a variety of members in the group based upon varying molecular and biochemical criteria, the most commonly accepted grouping includes $M$. tuberculosis, $M$. microti, $M$. africanum, $M$. bovis, and $M$. canetti. The organisms grow slowly and stain acid fast because of a highly 
lipid and peptidoglycan-rich cell wall. ${ }^{7}$ Evaluation of sputum smears and tissue samples is accomplished with two main stains: Ziehl-Neelsen and auramine orange fluorescence. ${ }^{3}$

A large, prospective study was conducted to evaluate the operational clinical performance of various technologies. ${ }^{8}$ Auramine orange fluorescence staining of three sputum samples per patient detected 7 of every 10 cases. The false-positive rate was 2 in 10 . In other studies with culture-proven disease, a single sputum sample detected disease in one-half to two-thirds of cases, while three or four specimens detected as many as 9 of every 10 cases. ${ }^{9,10}$ Most of the advantage in testing serial sputum specimens is gained with the second specimen collected. While spontaneous sputum samples are employed in many settings, use of induced sputum sampling confers an advantage. ${ }^{11}$ Both watery and viscous samples should be tested.

In most cases bronchoscopy for lavage is not required. It may be appropriate when sputum smears are negative in the setting of a known radiographic lesion allowing focused lavage. Induced sputum collection and bronchoalveolar lavage can be used together, detecting 8 of 10 patients. ${ }^{12}$ Simple instructions and coaxing can dramatically increase sputum smear yield. ${ }^{13}$

Auramine staining of sputum is superior. ${ }^{14,15}$ It has greater sensitivity with a requirement for fewer screened microscopic fields as a lower magnification can be used. Stain superiority in tissue samples is not clear. ${ }^{16,17}$ Typically, $10^{4}$ to $10^{6}$ organisms $/ \mathrm{ml}$ are required for detection, ${ }^{3,15}$ although concentration techniques can lower this number.

The hallmark finding on histopathology is the necrotizing or caseating granuloma. When found, tuberculosis should be presumed until disproven. The number of granulomas observed may vary by biopsy site-high numbers in the lung, low numbers in the bone marrow. ${ }^{18}$ Nontuberculosis mycobacteria also may cause necrotizing granulomas. HIV status may affect the observed histopathology of biopsy samples. ${ }^{19}$

\section{Culture}

Culture remains the gold standard for diagnosis. Egg-based plate media such as Löwenstein-Jensen are used, but agar media such as Selective 7H11 and liquid-based media (Becton-Dickinson and Co., BACTEC ${ }^{\text {TM }}$ and BACTEC ${ }^{\text {TM }}$ MGIT $^{\text {TM}}$ ) now are the standard. Some centers use all of these modalities to capture rare strains. ${ }^{3}$ Growth in liquid mediaautomated detection systems is monitored by radiometric, colorimetric, or pressure monitoring. Growth often can be detected within 2 weeks. Typical hold periods are for 4 to 6 weeks. Use of these systems also 
allows expeditious drug susceptibility assessment when agents are added into the liquid media.

M. tuberculosis grows at $37^{\circ} \mathrm{C}$ with a 5 to $10 \% \mathrm{CO}_{2}$ mixture. It can be distinguished from some atypical pathogens by its absence of growth at room temperature, beading when stained from media, and propensity to form cords on $7 \mathrm{H} 11$ agar. $^{20}$ With a generation time of over 12 hours, sample contamination and overgrowth by conventional bacteria is a continuing challenge. Biochemical assays may be used to distinguish $M$. tuberculosis from other members of the complex when molecular methods are not specific, such as growth in niacin, positive nitrate reduction test, and high-performance liquid chromatographic analysis. ${ }^{3}$ False-positive culture results may occur from laboratory contamination, or misidentification of an atypical mycobacterium. Pretreatment with a fluoroquinolone may delay diagnosis by more than 2 weeks, including delays in culture positivity. ${ }^{21,22}$

The Orange County study outpaced CDC data on culture yields. Solid media detected 3 of every 4 cases, but the BACTECTM 12B detected 19 of every 20 cases (SENS 95\%). ${ }^{8}$ Mean culture turnaround times were 18 days for BACTEC ${ }^{\text {TM }} 12 \mathrm{~B}$, and over 30 days for the solid media. No single modality captured all infections in this study.

Culture yields in extrapulmonary tuberculosis are significantly lower than from sputum samples. Improvements in sample processing for use in PCR have increased culture yields, resulting in detection of less than $10^{2}$ organisms $/ \mathrm{mL} .^{23,24}$ Pleural culture yields range from 23 to $67 \%$ from fluid, and 90 to $97 \%$ from biopsy. ${ }^{25}$ Despite high yields, finding providers to perform pleural biopsy is problematic.

All new culture isolates should be submitted for drug susceptibility testing. This requires submission to referral centers, or special requests of commercial laboratories.

\section{Molecular Methods: NAA/PCR}

NAA assays allow rapid turnaround time ( 24 to 48 hours) when samples are smear positive and can be done on smear-negative specimens, but with less sensitivity and specificity. They are performed directly on specially processed specimens to provide simultaneous detection and identification. Culture of the organism is still necessary to confirm the identification and to perform drug-sensitivity tests. Molecular targets usually include both an insertion sequence and a 16S rRNA sequence. A recent comprehensive review on PCR utility is available. ${ }^{26}$ Direct PCR tests must be explicitly ordered in most circumstances because of the added costs of the amplification technique. 
Two FDA-approved molecular tests are available for rapid diagnosis: a revised Amplified Mycobacterium Tuberculosis Direct Test (MTD) by Gen-Probe, and the Mycobacterium Tuberculosis Test (MTT) by Amplicor. $^{27}$ The Orange County study detected 9 of every 10 cases in 1 to 2 days with the revised MTD. ${ }^{8}$ PCR in sputum should be used to confirm diagnosis on a smear-positive specimen, though it has been used in primary diagnosis. ${ }^{28}$

Results in extrapulmonary testing demonstrate decreased sensitivity. One method incorporating both $\operatorname{dev} R$ and $I S 6110$ primers yielded positive results in two-thirds of cases of lymph node tuberculous disease. ${ }^{27}$

These are amplification tests. With positive culture material, a nonamplified sequence test can be performed. PCR sequences for M. avium intracellulare and M. kansasii also are available.

\section{Molecular Methods: Inflammatory Marker Measurements}

Inflammatory marker measurements exploit differences in the predominating immune response to different pathogens. Adenosine deaminase (ADA) and interferon gamma (IFN- $\gamma$ ) sometimes are used to diagnose tuberculous effusions. ${ }^{29}$ Other inflammatory markers also have been studied. ${ }^{30}$ These assays, too, may be compromised in immunocompromised patients. ${ }^{31}$ Combined PCR, ADA, and culture techniques have been used. ${ }^{32,33}$

QuantiFERON $^{\circledR}$-TB Gold Test (QFT-G) is discussed for LTBI elsewhere in this compendium. It has been studied in large cohorts, ${ }^{34-36}$ including HIV patients. ${ }^{37}$ Relative anergy during active disease can occur, though it may outperform TST. ${ }^{38,39}$ Other assays are under development. $^{40}$

\section{Fluid Cell Counts and Chemistries, Nonspecific Changes}

Fluid analysis may provide helpful clues in the diagnosis of tuberculosis. Involved pleural, pericardial, and CSF fluid may manifest neutrophilia, although a lymphocytosis eventually predominates. Protein is elevated and glucose levels may be low or low normal. Lactate dehydrogenase usually is elevated as effusions most often are exudative. Persistent sterile pyuria in an ill patient should raise suspicion for tuberculosis. Detailed descriptions of extrapulmonary tuberculosis findings are published. ${ }^{41}$

A wide range of nonspecific findings also may suggest tuberculosis. 
These changes are more prevalent with worsening disease. ${ }^{42}$ In pulmonary disease, up to three-quarters of moderately ill patients will have anemia with a low serum iron and total iron binding content, and erythrocyte sedimentation rate elevation. Half to two-thirds of patients will have a peripheral neutrophilia, monocytosis, and thrombocytosis. Rarer findings include lymphopenia, leukopenia, folic acid deficiency, macrocytic anemia, pancytopenia, and thrombocytopenia. Miliary disease may manifest an elevation of alkaline phosphatase, normal or mildly elevated hepatic transaminases and adrenal insufficiency. ${ }^{43}$

\section{Summary}

Laboratory diagnosis of tuberculosis requires a multimodality approach, as well as recognition that empiric therapy often is appropriate. New technologies such as proteomics and microarrays may soon find their place in the evaluation of patients. ${ }^{44,45}$ However, sputum and tissue analysis remain the cornerstone of laboratory diagnosis. Providers must be aware of how their laboratories process specimens, and which tests are an automatic part of evaluation. A direct PCR often must be requested separately.

\section{REFERENCES}

1. Centers for Disease Control and Prevention 2004 Surveillance Data, Reported Tuberculosis. www.cdc.gov/nchtsp/tb/surv2004/pdf/.

2. Centers for Disease Control and Prevention. Controlling tuberculosis in the United States: recommendations from the American Thoracic Society, CDC, and the Infectious Diseases Society of America. MMWR 2005;54(No. RR-12):1-81.

3. Heifets L, Desmond E. Clinical Mycobacteriology (Tuberculosis) Laboratory: Services and Methods. In: Cole ST, Eisenach L, McMurray DN, et al, editors. Tuberculosis and the Tubercle Bacillus. Washington DC: ASM Press, 2005. p. 49-60.

4. Diagnostic Standards and Classification of Tuberculosis in Adults and Children. This official statement of the American Thoracic Society and the Centers for Disease Control and Prevention was adopted by the ATS Board of Directors, July 1999. This statement was endorsed by the Council of the Infectious Disease Society of America, September 1999. Am J Respir Crit Care Med 2000 Apr;161(4 Pt. 1):1376-95.

5. Lee CH, Kim WJ, Yoo CG, et al. Response to empirical anti-tuberculosis treatment in patients with sputum smear-negative presumptive pulmonary tuberculosis. Respiration 2005 Jul-Aug;72(4):369-74.

6. Behr MA, Warren SA, Salamon $\mathrm{H}$, et al. Transmission of Mycobacterium tuberculosis from patients smear-negative for acid-fast bacilli. Lancet 1999 Feb 6; 353(9151):444-9.

7. Murray PR, Rosenthal KS, Kobayashi GS, et al. Mycobacterium. In: Murray PR, 
Rosenthal KS, Kobayashi GS, et al, editors. Medical Microbiology, 4th ed. St. Louis, MO: Mosby, Inc., 2002. p. 366-77.

8. Moore DF, Guzman JA, Mikhail LT. Reduction in turnaround time for laboratory diagnosis of pulmonary tuberculosis by routine use of a nucleic acid amplification test. Diagn Microbiol Infect Dis 2005 Jul;52(3):247-54.

9. Mixides G, Shende V, Teeter LD, et al. Number of negative acid-fast smears needed to adequately assess infectivity of patients with pulmonary tuberculosis. Chest 2005 Jul;128(1):108-15.

10. Finch D, Beaty CD. The utility of a single sputum specimen in the diagnosis of tuberculosis. Comparison between HIV-infected and non-HIV-infected patients. Chest 1997 May;111(5):1174-9.

11. Al Zahrani K, Al Jahdali H, Poirier L, et al. Yield of smear, culture and amplification tests from repeated sputum induction for the diagnosis of pulmonary tuberculosis. Int J Tuberc Lung Dis 2001;5(9):855-60.

12. Saglam L, Akgun M, Aktas E. Usefulness of induced sputum and fibreoptic bronchoscopy specimens in the diagnosis of pulmonary tuberculosis. J Int Med Res 2005 Mar-Apr;33(2):260-5.

13. Alisjahbana B, van Crevel R, Danusantoso $\mathrm{H}$, et al. Better patient instruction for sputum sampling can improve microscopic tuberculosis diagnosis. Int $\mathrm{J}$ Tuberc Lung Dis 2005 Jul;9(7):814-7.

14. Hanna BA. Laboratory Diagnosis. In: Rom WN, Garay SM, editors. Tuberculosis, 2nd ed. Philadelphia, PA: Lippincott Williams \& Wilkins, 2004. p. 163-76.

15. Strumpf IJ, Tsang AY, Sayre JW. Re-evaluation of sputum staining for the diagnosis of pulmonary tuberculosis. Am Rev Respir Dis 1979 Apr;119(4): 599-602.

16. Cheng AG, Chang A, Farwell DG, et al. Auramine orange stain with fluorescence microscopy is a rapid and sensitive technique for the detection of cervical lymphadenitis due to mycobacterial infection using fine needle aspiration cytology: a case series. Otolaryngol Head Neck Surg 2005 Sep;133(3):381-5.

17. Polesky A, Grove W, Bhatia G. Peripheral tuberculous lymphadenitis: epidemiology, diagnosis, treatment, and outcome. Medicine (Baltimore) 2005 Nov;84(6): 350-62.

18. Jogirdan J, Zagzag D. Pathology and insights into pathogenesis of tuberculosis. In: Rom WN, Garay SM, editors. Tuberculosis, 2nd ed. Philadelphia (PA): Lippincott Williams \& Wilkins, 2004. p. 323-44.

19. Reuter H, Burgess LJ, Schneider J, et al. The role of histopathology in establishing the diagnosis of tuberculous pericardial effusions in the presence of HIV. Histopathology 2006 Feb;48(3):295-302.

20. Plorde JJ, Mycobacteria. In: Ryan KJ, editor. Sherris Medical Microbiology: An Introduction to Infectious Diseases, 3rd ed. Stamford, CT: Appleton \& Lange, 1994. p. 401-15.

21. Dooley KE, Golub J, Goes FS, et al. Empiric treatment of community-acquired pneumonia with fluoroquinolones, and delays in the treatment of tuberculosis. Clin Infect Dis 2002 Jun 15;34(12):1607-12.

22. Yoon YS, Lee HJ, Yoon HI, et al. Impact of fluoroquinolones on the diagnosis of pulmonary tuberculosis initially treated as bacterial pneumonia. Int J Tuberc Lung Dis 2005 Nov;9(11):1215-9.

23. Chakravorty S, Tyagi JS. Novel multipurpose methodology for detection of 
mycobacteria in pulmonary and extrapulmonary specimens by smear microscopy, culture, and PCR. J Clin Microbiol 2005 Jun;43(6):2697-702.

24. Chakravorty S, Sen MK, Tyagi JS. Diagnosis of extrapulmonary tuberculosis by smear, culture, and PCR using universal sample processing technology. J Clin Microbiol 2005 Sep;43(9):4357-62.

25. Kamholz SL. Pleural tuberculosis. In: Rom WN, Garay SM, editors. Tuberculosis, 2nd ed. Lippincott Williams \& Wilkins, Philadelphia, PA: 2004;497-507.

26. Cheng VC, Yew WW, Yuen KY. Molecular diagnostics in tuberculosis. Eur J Clin Microbiol Infect Dis 2005 Nov;24(11):711-20.

27. Centers for Disease Control and Prevention. Notice to Readers: Update: nucleic acid amplification tests for tuberculosis. MMWR 2000 Jul 07;49(26):593-4.

28. Laifer G, Widmer AF, Frei R, et al. Polymerase chain reaction for Mycobacterium tuberculosis: impact on clinical management of refugees with pulmonary infiltrates. Chest 2004 Mar;125(3):981-6.

29. Greco S, Girardi E, Masciangelo R, et al. Adenosine deaminase and interferon gamma measurements for the diagnosis of tuberculous pleurisy: a meta-analysis. Int J Tuberc Lung Dis 2003 Aug.;7(8):777-86.

30. Hiraki A, Aoe K, Eda R, et al. Comparison of six biological markers for the diagnosis of tuberculous pleuritis. Chest 2004 Mar;125(3):987-9.

31. Gaga M, Papamichalis G, Bakakos P, et al. Tuberculous effusion: ADA activity correlates with CD4+ cell numbers in the fluid and the pleura. Respiration 2005 Mar-Apr;72(2):160-5.

32. Lima DM, Colares JK, da Fonseca BA. Combined use of the polymerase chain reaction and detection of adenosine deaminase activity on pleural fluid improves the rate of diagnosis of pleural tuberculosis. Chest 2003 Sep;124(3):909-14.

33. Villegas MV, Labrada LA, Saravia NG. Evaluation of polymerase chain reaction, adenosine deaminase, and interferon-gamma in pleural fluid for the differential diagnosis of pleural tuberculosis. Chest 2000 Nov;118(5):1355-64.

34. Mazurek GH, Jereb J, Lobue P, et al. Division of Tuberculosis Elimination, National Center for HIV, STD, and TB Prevention, Centers for Disease Control and Prevention (CDC). Guidelines for using the QuantiFERON-TB Gold test for detecting Mycobacterium tuberculosis infection, United States. MMWR Recomm Rep 2005 Dec 16;54(RR-15):49-55.

35. Porsa E, Cheng L, Seale MM, et al. Comparison of a new ESAT-6/CFP-10 peptide-based gamma interferon assay and a tuberculin skin test for tuberculosis screening in a moderate-risk population. Clin Vaccine Immunol 2006 Jan;13(1):53-8.

36. Dewan PK, Grinsdale J, Liska S, et al. Feasibility, acceptability, and cost of tuberculosis testing by whole-blood interferon-gamma assay. BMC Infect Dis 2006 Mar 15;6:47.

37. Brock I, Ruhwald M, Lundgren B, et al. Latent tuberculosis in HIV positive, diagnosed by the M. tuberculosis specific interferon gamma test. Respir Res 2006 Apr 1;7(1):56.

38. Demissie A, Leyten EM, Abebe M, et al; the VACSEL Study Group. Recognition of stage-specific mycobacterial antigens differentiates between acute and latent infections with Mycobacterium tuberculosis. Clin Vaccine Immunol 2006 Feb;13(2):179-86.

39. Ferrara G, Losi M, Meacci M, et al. Routine hospital use of a new commercial 
whole blood interferon-gamma assay for the diagnosis of tuberculosis infection. Am J Respir Crit Care Med 2005 Sep 1;172(5):631-5.

40. Meier T, Eulenbruch HP, Wrighton-Smith P, et al. Sensitivity of a new commercial enzyme-linked immunospot assay (T SPOT-TB) for diagnosis of tuberculosis in clinical practice. Eur J Clin Microbiol Infect Dis 2005 Aug;24(8):529-36.

41. Iseman MD. A Clinician's Guide to Tuberculosis. Philadelphia, PA: Lippincott Williams \& Wilkins, 2000.

42. Garay S. Pulmonary Tuberculosis. In: Rom WN, Garay SM, editors. Tuberculosis, 2nd ed. Philadelphia, PA, Lippincott Williams \& Wilkins, 2004. p. 345-94.

43. Baker SK, Glassroth J. Miliary Tuberculosis. In: Rom WN, Garay SM, editors. Tuberculosis, 2nd ed. Philadelphia, PA, Lippincott Williams \& Wilkins, 2004. p. 427-44.

44. Attallah AM, Osman S, Saad A, et al. Application of a circulating antigen detection immunoassay for laboratory diagnosis of extra-pulmonary and pulmonary tuberculosis. Clin Chim Acta 2005 Jun;356(1-2):58-66.

45. Tong M, Jacobi CE, van de Rijke FM, et al. A multiplexed and miniaturized serological tuberculosis assay identifies antigens that discriminate maximally between TB and non-TB sera. J Immunol Methods 2005 Jun;301(1-2):154-63. 